\title{
Laboratory sessions and experiments paradoxes
}

\begin{abstract}
During research and experimentation in the laboratory, interesting phenomena are sometimes observed. Some arise in preparation for work, others during, others in random, purposeless experiments with the equipment available. Only a few of the observed ones are considered here. Some of phenomena are subjects to further research, such as rotation of various materials in electric field.
\end{abstract}

Keywords: phenomena, rotation, pulsations, water, magnets, laboratory, electric field, high voltage

\author{
Volume 4 Issue 4 - 2020
}

\section{Korotaev BA}

Department of Offshore Oil and Gas Exploration, MSTU, Russia

Correspondence: Korotaev BA, Department of Offshore Oil and Gas Exploration, MSTU, Russia,

Email korotevba@mstu.edu.ru

Received: April 14, 2020 | Published: August 18, 2020

\section{Introduction}

There are some interesting phenomena happening while working in lab. One of those was noticed upon preparation of another lab work on research of gas dynamics. Researchers were measuring a distribution of gas flow pressure in horizontal tube with manometric tubes filled with water. Figure 1 shows a scheme of the laboratory installation. All dimensions are given in millimeters. Gas flow in tube was provided by air compressor. In the process of work the leftmost gauge tube suddenly fell down and some amount of water leaked out of it. The situation is shown on Figure 2. It was noticed that level of water in other tubes was fluctuating periodically. It was happening until the installation was fixed: the fallen tube was mounted back on its place and replenished. After that fluctuating of water level discontinued. Conclusion: Repeated attempts to reproduce the phenomenon of water level fluctuation in the tubes (even providing the same experiment conditions) failed. Similar pulsations appear in real pipelines, example shown below on Figure 3.

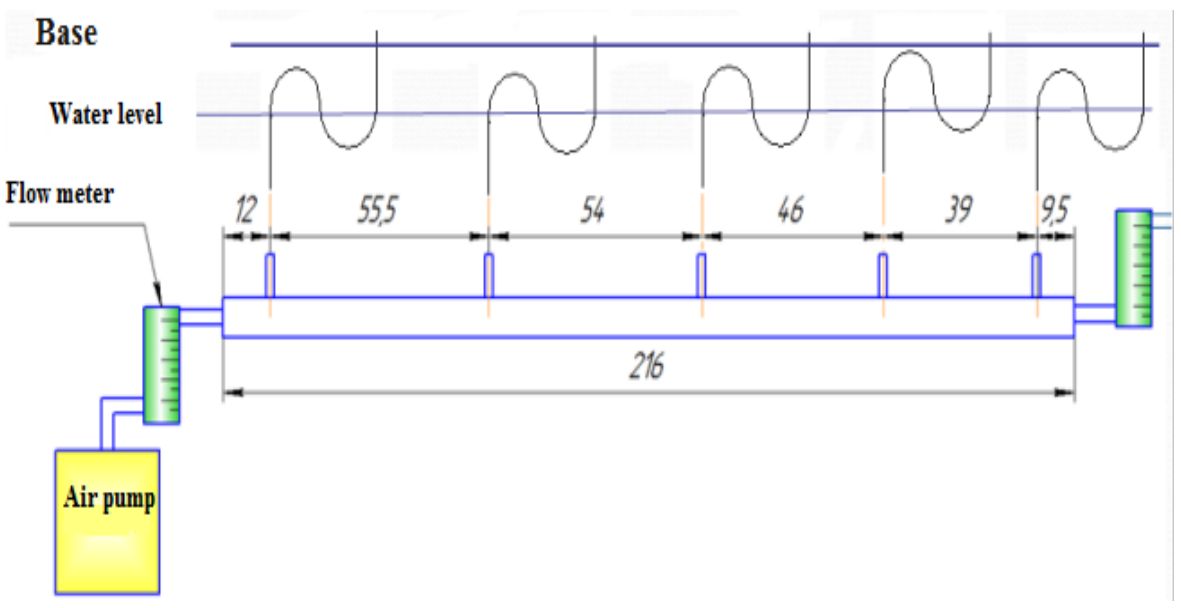

Figure I The scheme of the laboratory installation.

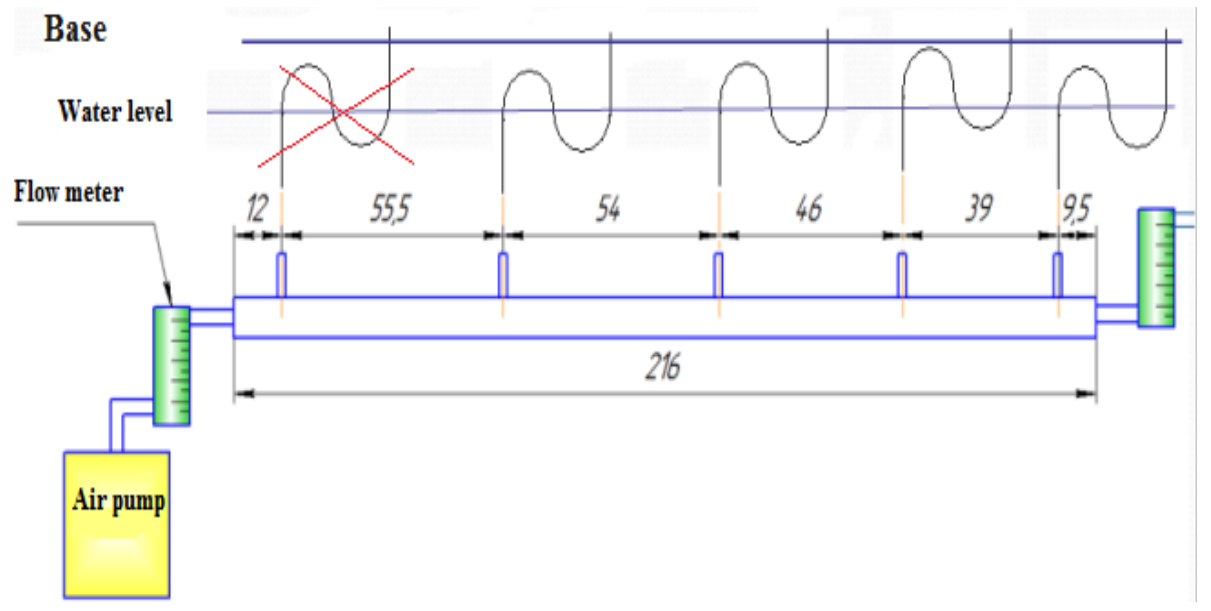

Figure $2 \mathrm{~A}$ scheme of the laboratory installation with manometric tubes. 


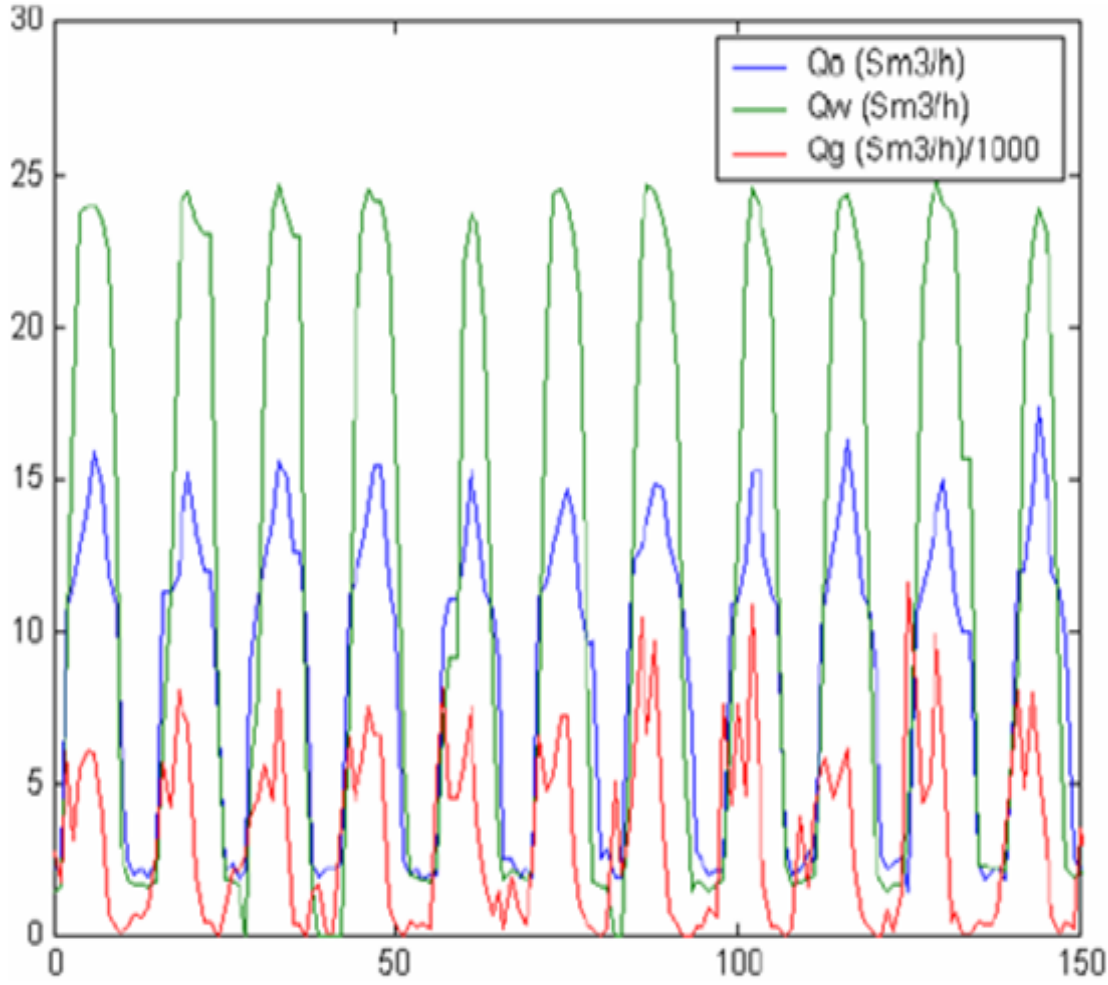

Figure 3 Pulsation of flow rate at the control point of the pipeline in time.

\section{Data taken from Norsk Hydro AS}

Let's process one impulse of flow rate in time. To do this, according to Figure 3, we reproduce one pulse of oil consumption. The initial data is: the nominal diameter of the pipe is $580 \mathrm{~mm}$ (22.8in), the density of oil is $850 \mathrm{~kg} / \mathrm{m}^{3}\left(53.1 \mathrm{lbs} / \mathrm{ft}^{3}\right)$, the pressure inside the pipe is $5 \mathrm{MPa}(725 \mathrm{psi})$. For these conditions, we calculate and construct a graph of oil velocity $(\mathrm{m} / \mathrm{s})$ as a function of time (minutes) (Figure 4$)$.

It is possible to determine the pressure pulsations in the pipe now (Figure 5).

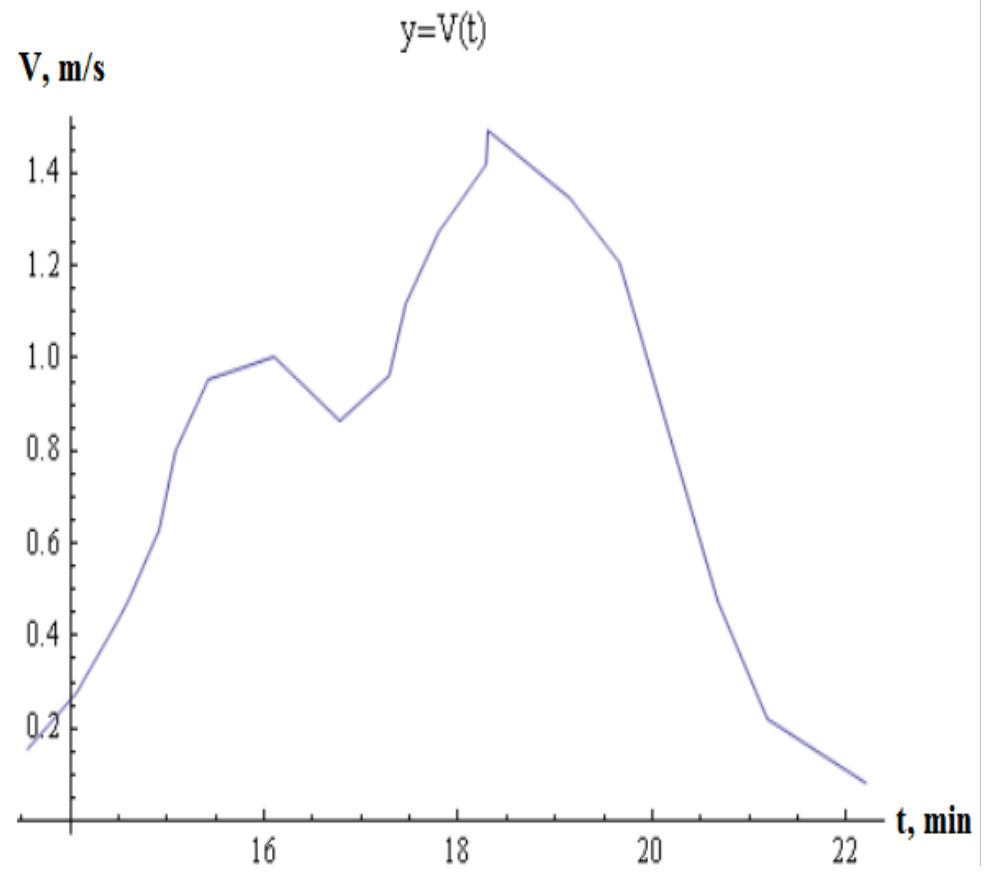

Figure 4 The distribution of changes in the rate of oil on time. 


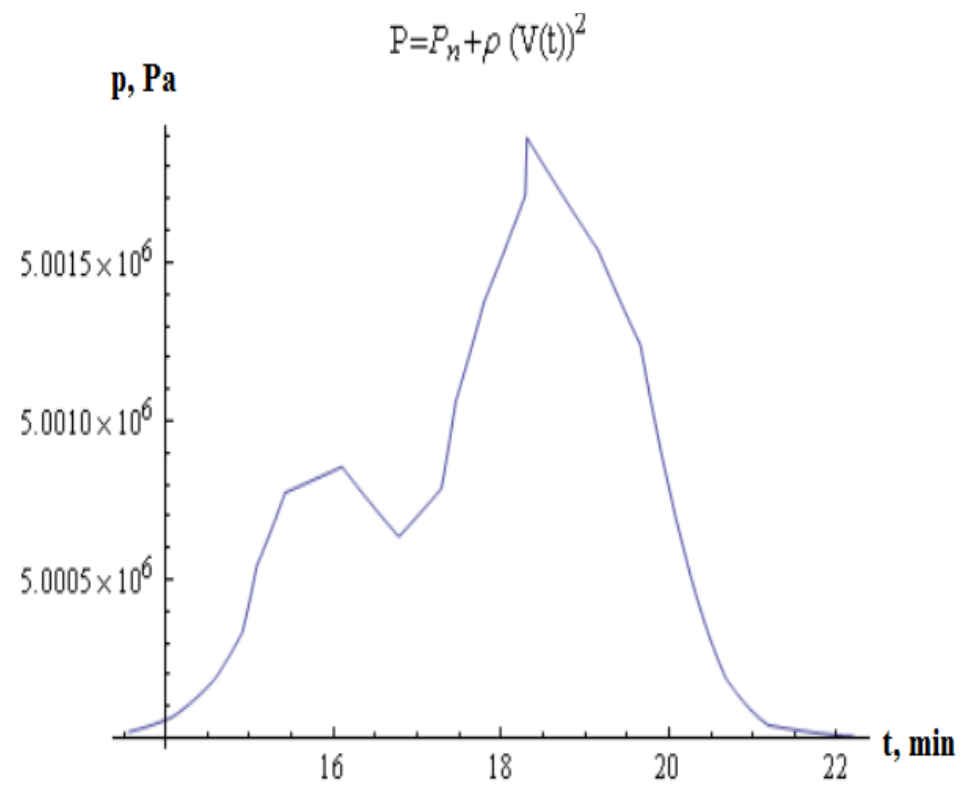

Figure 5 Pulsation of oil pressure in the pipe.

i. The other case is related to magnets. Someone put two magnets in a cylindrical glass jar. It was noticed that they oriented the way as shown on Figure 6.

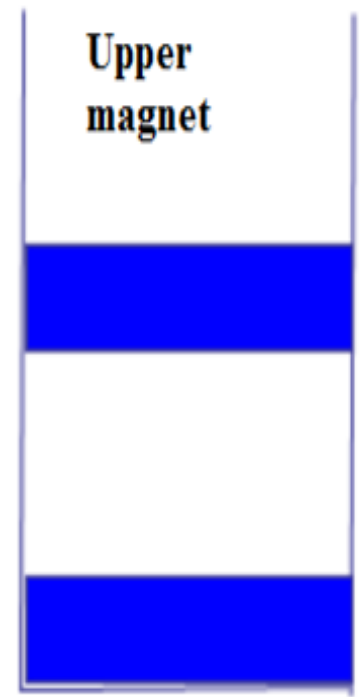

\section{Bottom magnet}

Figure 6 The position of the magnets inside the jar.

It occured that the upper magnet stood over the lower one. Magnets had been staying in this state for some time before someone tried to take upper magnet away. Upon that attempt the upper magnet turned and landed on the lower magnet. As a result both of them splitted into pieces and jar bottom was cracked.

Conclusion: It was not possible to reproduce the observed phenomenon of free hanging of one magnet over another (when repeating the experiment).

ii. The third case happened while preparing graduate work. The research was related to increased stress inside rock caves caused by frozen water. There was made an experiment to obtain some data. A cylindrical beaker filled with water was placed into freezer to get some amount of ice. The next day upon taking the glass with ice within, one noticed an interesting thing (Figure 7).

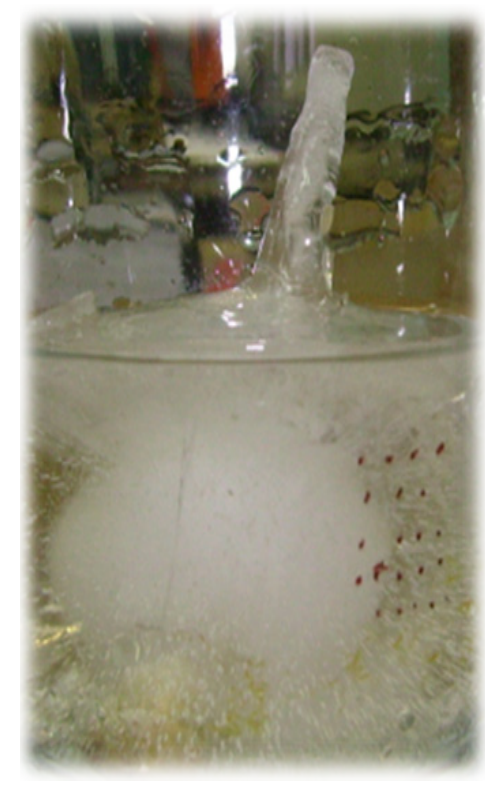

Figure 7 "Icicle" in a beaker.

It occured that for unknown reasons water froze in that strange way as shown on picture (Figure 7).

Conclusion: Unfortunately, another attempts to achieve that result failed.

iii. Fourth case:The next interesting thing was observed during experiments of comparing minimal breakdown voltage of various materials. Someone noticed that some objects were rotating while hanging between two electrodes. In Figure 8 is an illustration of the rotation of objects suspended in a string in an electric field (Table 1). 
Someone suggested to check wide range of materials whether they rotate or not. There was used a device generating high voltage $(\sim 30 \mathrm{kV})$.

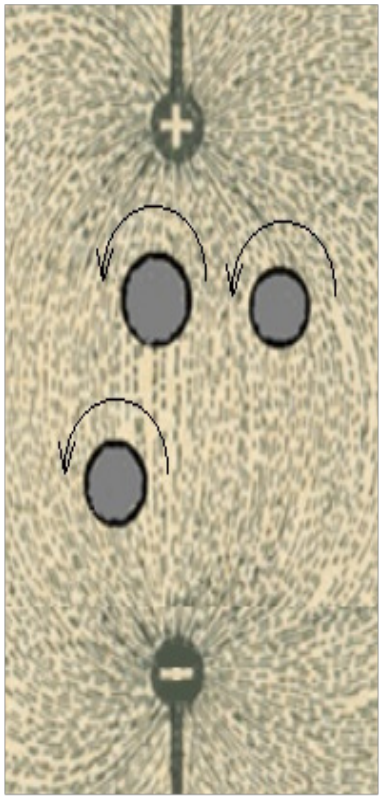

Figure 8 The rotation of objects in the electric field.

Table I List of tested materials

\begin{tabular}{ll}
\hline Material & Rotation \\
\hline Plasticine & + \\
Paraffin & + \\
Charcoal & - \\
Wet clay & - \\
Dry clay & - \\
Rubber & + \\
Porcelain & - \\
Marble & + \\
Ferruginous quartzite & + \\
Rock & + \\
Dry wood & - \\
Granite & + \\
Glass & + \\
Sandstone & + \\
Granite & + \\
Tar & + \\
\hline
\end{tabular}

Table Continued...

\begin{tabular}{ll}
\hline Material & Rotation \\
\hline Obsidian & + \\
Natural gypsum & + \\
Jade & + \\
Styrofoam & + \\
Sandstone infused with oil & + \\
Plexiglas & + \\
Magnet & - \\
Stone & + \\
Slate & - \\
Ice & + - \\
Basalt & + \\
Dolomite & + \\
Pyroxenite & + \\
Galit & + \\
Bauxite & + \\
Flint & + \\
Galit+Sylvite & + \\
Argillite & + \\
Rosin & + \\
\hline
\end{tabular}

«+» means that object rotates, «-» means that it does not

\section{Conclusion}

Sometimes it is hard to achieve the same results providing even the same conditions of experiment. For example, some materials that were marked as "able to rotate in electric field" suddenly began to behave themselves in other way: they oscillated between electrodes without turning round. Also noticed that results are susceptible to arrangement of electrodes, extrinsic objects lying around experimental equipment, current air humidity, etc.

\section{Acknowledgments}

None.

\section{Conflicts of interest}

The authors declares that there is no conflict of interest.

\section{References}

1. Surovtseva NA, Danilov PN. MSTU, ELB-1, NDb-1 Scientific adviser Korotaev BA. Collection of materials of the All-Russian student scientific and technical SNTK conferences - 2019. Ministry science and higher education of the Russian Federation, FSBEI HE Murman state tech University. Murmansk: Publishing House of MSTU. 2019; 302 p. 